\title{
TOTOBUANG
}

Volume $6 \quad$ Nomor 2, Desember 2018 Halaman 183-199

\section{TUTURAN DALAM PROSESI LAMARAN PERNIKAHAN DI TOMIA KABUPATEN WAKATOBI \\ (Speech In The Wedding Purpose Procession In Tomia Kabupaten Wakatobi)}

\author{
Risman Iye \\ Universitas Iqra Buru \\ Jl. Prof. Dr. H. A.R. Basalamah No. 20, Namlea-Kab. Buru \\ Pos-el: rismaniye@gmail.com
}

(Diterima: 16 Oktober 2018; Direvisi: 15 November 2018; Disetujui: 19 Desember 2018)

\begin{abstract}
Purpose procession is a sacred process that is occupied by a part of society is an obligation of a culture. the event is not only present instantaneously, but requires a long process with various stages. So does marriage at Tomia Wakatobi. This study aims to describe the form of speech in the marriage purpose procession in Tomia and explain the meaning of speech in the process. This research is a kind of qualitative descriptive research Field Research, which is based on the results obtained through field research. Regarding the object discussed according to the reality that occurs in society, especially in the community in the East Tomia Subdistrict, Wakatobi Regency. The results showed that the stages in the purpose process in Tomia consisted of four forms. 1) Pa'epe. 2) Pa'rara; 3) Po'ema-ema and 4) Nga'a Nualo. Of the four forms of application processions the utterances spoken vary. On form Pa'epe, Pa'rara and Nga'a Nualo the form of the speech is declarative and interrogative. while in form Po'ema-ema the form of the speech is in the form of declarative, imperative and interrogative. The meaning in the speech purpose procession means connotation.
\end{abstract}

Keywords: speech, purpose, weeding, Tomia

\begin{abstract}
Abstrak
Prosesi lamaran merupakan proses sakral yang dianggap oleh sebagian masyarakat adalah kewajiban dari suatu budaya. Peristiwa tersebut bukan hanya hadir secara instan, namun memerlukan proses yang panjang dengan berbagai tahapan. Begitu pula pernikahan di Tomia Wakatobi. Penelitian ini bertujuan mendeskripsikan wujud tuturan dalam prosesi lamaran pernikahan di Tomia dan menjelaskan makna tuturan dalam prosesinya. Penelitian ini merupakan jenis penelitian deskriptif kualitatif Field Research, yaitu berdasarkan hasil yang diperoleh melalui penelitian lapangan. Mengenai objek yang dibicarakan sesuai kenyataan yang terjadi di masyarakat khususnya pada masyarakat di Kecamatan Tomia Timur, Kabupaten Wakatobi. Hasil penelitian menunjukkan bahwa tahapan dalam proses lamaran di Tomia terdiri atas empat bentuk. 1) Pa'epe. 2) Pa'rara; 3) Po'ema-ema, dan 4) Nga'a Nualo. Dari keempat bentuk prosesi lamaran tersebut tuturan yang dituturkan bervariasi. Pada bentuk Pa'epe, Pa'rara, dan Nga'a Nualo wujud tuturannya berbentuk deklaratif, dan interogatif. Akan tetapi pada tahapan Po'ema-ema wujud tuturannya berbentuk deklaratif, imperatif, dan interogatif. Makna dalam tuturan prosesi lamaran bermakna konotasi.
\end{abstract}

Kata-Kata Kunci: tuturan, lamaran, pernikahan, Tomia

\section{PENDAHULUAN}

Indonesia terdiri dari berbagai suku bangsa yang memiliki bermacam-macam adat dalam prosesi lamaran pernikahan, misalnya suku Jawa, suku Cina, suku Melayu, suku Bugis, dan masih banyak lagi. Keberagaman adat dalam prosesi lamaran pernikahan tersebut tak terkecuali pula di Kabupaten Wakatobi khususnya Kecamatan Tomia. Dalam prosesi lamaran pernikahan tidak terlepas dari unsur yang menyertainya, yakni bahasa.

Tomia merupakan kecamatan yang ada di Kabupaten Wakatobi. Provinsi Sulawesi Tenggara yang mempunyai banyak praktik-praktik kebudayaan salah satunya prosesi lamaran pernikahan dengan menggunakan bahasa-bahasa pengantar yang masih berbentuk bahasa kiasan. Bahasa kiasan tersebut bertujuan untuk 
memperhalus maksud dari penutur ke petutur (pihak keluarga laki-laki dengan pihak keluarga perempuan).

Lamaran merupakan tahapan sebelum prosesi pernikahan untuk saling mengenal lebih jauh keluarga laki-laki dan keluarga perempuan. Pernikahan merupakan institusi yang sangat penting dalam masyarakat. Adat lamaran pernikahan yang bermacammacam menunjukkan latar belakang wujud prosesi lamaran pernikahan adat yang berbeda-beda. Kenyataan kehidupan serta alam Indonesia dengan sendirinya membuat bangsa Indonesia untuk saling berbeda selera dan kebiasaan budaya, adat serta tradisi.

Salah satu dari perbedaan kebiasaan tersebut adalah masalah pelaksanaan prosesi lamaran pernikahan. Keberagaman suku bangsa di Indonesia juga berpengaruh terhadap sistem dalam lamaran pernikahan di masyarakat. Masyarakat Wakatobi khususnya Tomia, menjunjung tinggi adat istiadat yang sudah turun-temurun. Adat istiadat tersebut sudah menjadi ketetapan adat yang harus diikuti oleh semua lapisan masyarakat Tomia. Ketetapan adat tersebut menyangkut hal yang paling peka dalam diri masyarakat Tomia seperti harga diri, kehormatan, dan nama baik keluarga. Kepekaan itulah yang harus dipelihara dan ditegakkan oleh masyarakat Tomia dalam kehidupannya sehari-hari.

Salah satu cara menghargai ketetapan tersebut, yakni dengan adanya prosesi lamaran pernikahan karena merupakan suatu sistem nilai budaya yang memberi arah dan pandangan untuk mempertahankan nilai-nilai hidup, terutama dalam hal mempertahankan dan melestarikan budaya atau adat. Bagi masyarakat di Wakatobi khususnya Tomia dan masyarakat di Indonesia pada umumnya, prosesi lamaran pernikahan adalah suatu proses untuk ke arah penyatuan dua keluarga besar dari kedua calon mempelai. Prosesi adat lamaran pernikahan di Tomia merupakan salah satu kebudayaan masyarakat yang sekarang ini masih belum usang di kalangan para sejarawan. Prosesi adat lamaran pernikahan masyarakat Tomia merupakan pranata yang dilaksanakan atas dasar budaya dan aturanaturan adat setempat.

Prosesi lamaran pernikahan di Wakatobi banyak dipengaruhi oleh ritualritual sakral dengan tujuan agar prosesi lamaran berjalan dengan lancar dan kedua calon mempelai mendapat berkah dari Tuhan. Bagi mayoritas penduduk Indonesia, sebelum memutuskan untuk menikah biasanya harus melalui tahapan yang menjadi prasyarat bagi pasangan tersebut. Tahapan tersebut diantaranya adalah masa perkenalan atau kemudian setelah masa ini dirasa cocok, maka mereka akan melalui tahapan berikut, yaitu meminang. Peminangan adalah kelanjutan dari masa perkenalan dan masa berkencan. Selanjutnya, setelah perkenalan secara formal melalui peminangan tadi, maka dilanjutkan dengan melaksanakan pertunangan sebelum akhirnya mereka memutuskan untuk melaksanakan pernikahan (Takariawan, 2004).

Hal yang diungkapkan oleh Takariwan di atas berlaku pula di Tomia. Masyarakat Tomia dalam memutuskan suatu pernikahan harus melalui tahapantahapan yang menjadi syarat utama. Tahapan-tahapan ini bertujuan untuk menampakkan rasa menghormati dan menghargai antarkedua pihak keluarga. Sebagai gambaran, adapun tahapan-tahapan prosesi lamaran dalam adat Tomia Kabupaten Wakatobi meliputi (1) tahap Pa'epe, (2) tahap Pa'rara, (3) tahap Po'ema-ema, (4) tahap Nga'a Nualo. Keempat tahapan tersebut saling berkesinambungan. Artinya, jika pada tahap pertama tidak terealisasi, tahap-tahap selanjutnyapun tidak akan terealisasi.

Perkawinan merupakan salah satu praktik kebudayaan yang dipercayai, sebagai perwujudan ideal hubungan cinta antara dua individu dan telah menjadi 
urusan banyak orang atau institusi, mulai dari orang tua, keluarga besar, institusi agama sampai Negara. Pernikahan bertujuan membentuk keluarga yang diliputi rasa saling cinta mencintai dan rasa kasih sayang antara sesama anggota keluarga.

Penelitian ini bertujuan mendeskripsikan wujud tuturan dalam prosesi lamaran pernikahan di Tomia dan menjelaskan makna tuturan dalam prosesi lamaran pernikahan di Tomia.

\section{LANDASAN TEORI}

\section{Semantik}

Semantik memegang peranan penting dalam berkomunikasi. Disebabkan bahasa memiliki fungsi dan tujuan untuk digunakan dalam berkomunikasi dalam menyampaikan suatu makna (Sutedi, 2003). Seperti seseorang yang menyampaikan suatu ide dan pikiran kepada lawan bicara, lalu lawan bicara mampu untuk memahami apa yang disampaikan.

Semantik sebagai tataran linguistik yang mempelajari makna tidak terbatas pada makna kata, tetapi juga makna kalimat. Sering dikenal juga dengan semantik leksikal dan semantik gramatikal (Rohmadi, 2010).

Makna akan bahasa terdiri atas berbagai macam jenis yang ditempatkan pada konteks penggunaan kalimat. Sehingga dalam memberikan suatu analisis semantik terlebih dahulu disadari bahwa bahasa memiliki sifat unik dan memiliki hubungan erat dengan masalah budaya.

Palmer (1981) mengatakan bahwa semantik adalah semantics is the technical term used to refer to the study of meaning, and since meaning is part of language, semantics is a linguistic. Semantik merupakan istilah yang teknik yang merujuk dalam suatu studi tentang makna, dan karena makna merupakan bagian dari bahasa, maka semantik merupakan bagian dari linguistik.

\section{Ujaran}

Jika diamati secara saksama jelas terlihat bahwa studi semantik bersifat diadis dan internal. Maksudnya bahwa bahasa dipandang sebagai sebuah entitas yang memiliki dua elemen, yakni elemen bentuk (bunyi, suku kata, frasa, klausa, kalimat, dan wacana) dan elemen makna. Dalam pandangan Morris dan Saussure, studi semantik berbicara tentang relasi bentuk kebahasaan sebagai penandanya (signifiant) dengan makna sebagai petandanya (signifie). Sementara itu, unsurunsur bahasa yang mengandung penanda dan petanda disebut sebagai tanda kebahasaan (sign).

Menurut Parera (dalam Rohmadi, 2010) mengatakan bahwa konsep ujaran berhubungan dengan manifestasi bahasa dalam bentuk lisan. Tutur merupakan ujaran lisan atau rentang perbincangan yang didahului dan diakhiri dengan kesenyapan pada pihak penutur. Sebuah tutur adalah penggunaan sepenggal bahasa, seperti rentetan kalimat, sebuah frase, atau sepatah kata oleh penutur pada kesempatan tertentu.

Ujaran juga merupakan tuturan kalimat yang dilisankan. Untuk mengetahui makna ujaran tidak dapat hanya dilihat dari satu sisi ujaran itu sendiri, tetapi perlu diperhatikan situasi atau kontekstualnya (Rohmadi, 2010).

\section{Kalimat}

Richards (dalam Rohmadi, 2010) dalam Longman Dictionary of Applied Linguistics mengatakan bahwa sentence is The largest unit of grammatical organization within which parts of speech (eg. Nouns, verbs, adverbs) and grammatical classes (eg. Words, phrase, clause) are said to function (kalimat adalah salah satu kesatuan unit gramatikal yang terluas dengan bagianbagiannya dikatakan sebagai kata benda, 
kata kerja, kata keterangan, dan berfungsi sebagai kelas kata, frasa, dan klausa).

Setiap satuan kebahasaan dari tataran morfem, kata, klausa, kalimat, paragraf, dan wacana memiliki makna. Setiap kalimat memiliki arti. Kalimat ditentukan berdasarkan arti sebagai susunan kata-kata yang menyatakan suatu maksud atau buah pikiran, juga digolongkan berdasarkan atas arti kalimat berita, kalimat tanya, kalimat suruh, kalimat larangan dan sebagainya (Ramlan, 1983).

Ramlan (1983) menyatakan bahwa berdasarkan fungsinya dalam hubungan situasi, kalimat digolongkan menjadi tiga golongan, yakni:

\section{a. Kalimat Berita (Deklaratif)}

Kalimat berita menurut fungsinya dalam hubungan situasi pada umumnya berfungsi untuk memberitahukan sesuatu kepada orang lain hingga tanggapan yang diharapkan hanyalah berupa perhatian.

\section{b. Kalimat Tanya (Interogatif)}

Kalimat tanya umumnya berfungsi untuk menanyakan sesuatu. Pola intonasi akhir kalimat tanya adalah naik dan diakhiri dengan tanda tanya (?).

c. Kalimat Perintah atau Suruh (Imperatif)

Kalimat perintah berfungsi untuk menyuruh/memerintah lawan bicaranya. Artinya, penutur mengharapkan tanggapan yang berupa tindakan dari orang yang diajak bicara.

\section{Makna}

Makna (pikiran atau referensi) adalah hubungan antara lambang (simbol) dan acuan atau referen. Hubungan antara lambang dan acuan bersifat tidak langsung sedangkan hubungan antara lambang dengan referensi dan referensi dengan acuan bersifat langsung (Ogden dan Richards dalam Sudaryat, 2009:13). Batasan makna ini sama dengan istilah pikiran, referensi yaitu hubungan antara lambang dengan acuan atau referen (Ogden dan Richards dalam Sudaryat, 2009:13) atau konsep (Lyons dalam Sudaryat, 2009:13). Secara linguistik makna dipahami sebagai apa-apa yang diartikan atau dimaksudkan oleh kita (Hornby dalam Sudaryat, 2009:13).

Jika seseorang menafsirkan makna sebuah lambang, berarti orang tersebut memikirkan sebagaimana mestinya tentang lambang tersebut, yakni sesuatu keinginan untuk menghasilkan jawaban tertentu dengan kondisi-kondisi tertentu (Stevenson dalam Pateda, 2001:82).

\section{Lamaran/Pinangan}

Kata peminangan berasal dari kata pinang, meminang (kata kerja). Meminang sinonimnya adalah melamar yang dalam bahasa Arab disebut khitbah. Secara etimologi, meminang atau melamar artinya "meminta wanita untuk dijadikan istri (bagi diri sendiri atau orang lain)".

Peminangan (lamaran) dilakukan sebagai permintaan secara resmi kepada wanita yang akan dijadikan calon istri atau melalui wali wanita itu. sesudah itu baru dipertimbangkan apakah lamaran itu dapat diterima atau tidak. Adakalanya lamaran itu hanya sebagai formalitas saja, sebab sebelumnya antara pria dan wanita itu sudah saling mengenal atau menjajaki. Demikian juga, lamaran itu adakalanya sebagai langkah awal dan sebelumnya tidak pernah kenal secara dekat, atau hanya kenal melalui teman atau sanak keluarga (Hasan, 2006).

Agaknya Islam mengajarkan sebelum terjadinya akad nikah, mempelai laki-laki dan perempuan mestilah saling mengenal. Saling mengenal maksudnya bukan sekadar mengetahui namun juga memahami dan mengerti akan kepribadian masing-masing. Hal ini dipandang penting karena kedua mempelai akan mengikatkan diri dalam sebuah perkawinan dan membentuk keluarga yang semula dimaksudkan "kekal" tanpa adanya perceraian. Realitas di masyarakat 
menunjukkan perceraian sering kali terjadi karena tidak adanya saling pengertian, saling memahami, dan menghargai masing-masing pihak.

Dalam perspektif Islam, peminangan itu lebih mengacu untuk melihat kepribadian calon mempelai wanita seperti ketakwaan, keluhuran budi pekerti, kelembutan dan ketulusannya. Kendati demikian bukan berarti masalah fisik tidak penting. Ajaran Islam ternyata menganjurkan untuk memperhatikan hal-hal yang bersifat lahiriah seperti kecantikan wajah, keserasian, kesuburan dan kesehatan tubuh. bahkan ada hadis rasul yang memerintahkan untuk menikahi wanita yang subur (al-walud) (Nuruddin, 2006).

Lamaran merupakan sebuah tradisi ketika pihak dari calon mempelai pria datang bersama anggota keluarganya, termasuk kedua orang tuanya, ke tempat calon mempelai wanita untuk meminta atau meminang wanita untuk di jadikan istrinya. Lamaran sebagai salah satu warisan budaya dan merupakan tradisi bagi masyarakat.

Syarat-syarat wanita yang boleh dipinang terdapat pada pasal 12 Kompilasi Hukum Islam (KHI), yang berbunyi:

a. Peminangan dapat dilakukan terhadap seorang wanita yang masih perawan atau terhadap janda yang telah habis masa iddahnya.

b. Wanita yang ditalak suami yang masih berada dalam masa iddah raj'iyyah, haram dan dilarang untuk dipinang.

c. Dilarang juga meminang seorang wanita yang sedang dipinang orang lain selama pinangan pria tersebut belum putus atau belum ada penolakan dari pihak wanita.

d. Putusnya pinangan untuk pria karena adanya pernyataan tentang putusnya hubungan pinangan atau secara diam-diam. Pria yang telah meminang telah menjauhi dan meninggalkan wanita yang dipinang. Pinangan atau lamaran seorang laki- laki kepada seorang perempuan boleh dengan ucapan langsung maupun secara tertulis. Meminang perempuan sebaiknya dengan sindiran. dalam meminang dapat dilakukan dengan tanpa melihat wajahnya, juga dapat melihat wanita yang dipinangnya.

Sebagaimana sebuah tuntutan, peminangan memiliki banyak hikmah dan keutamaan. Peminangan bukan sekadar peristiwa sosial, juga bukan semata-mata peristiwa ritual. Ia memiliki sejumlah keutamaan yang membuat pernikahan yang akan dilakukan menjadi lebih berkah. Di antara hikmah yang terkandung dalam peminangan atau khitbah adalah.

a. Memudahkan jalan perkenalan antara peminang dan yang dipinang beserta kedua belah pihak. Dengan pinangan, maka kedua belah pihak akan saling menjajaki kepribadian masing-masing dengan mencoba melakukan pengenalan secara mendalam.

b. Menguatkan tekad untuk melaksanakan pernikahan. Pada awalnya laki-laki atau perempuan berada dalam keadaan bimbang untuk memutuskan melaksanakan pernikahan.

\section{METODE PENELITIAN \\ Jenis Penelitian dan Pendekatan}

Penelitian ini merupakan penelitian deskriptif kualitatif dengan jenis Field Research, yaitu berdasarkan hasil yang diperoleh melalui penelitian lapangan. Mengenai objek yang dibicarakan sesuai kenyataan yang terjadi di masyarakat khususnya pada masyarakat Tomia, Kabupaten Wakatobi.

Pendekatan yang digunakan dalam penelitian ini adalah pendekatan semantik. Pendekatan semantik adalah pendekatan untuk melihat bentuk ujaran serta memaknai bentuk ujaran tersebut. 


\section{Sumber dan Jenis Data}

Sumber data yang diperlukan dalam penelitian ini adalah data yang diperoleh dari narasumber atau informan, dalam hal ini pemuka adat atau beberapa tokoh masyarakat setempat.

Jenis data yang digunakan dalam penelitian ini adalah tuturan atau ujaran yang berbentuk lisan.

\section{Metode dan Teknik Pengumpulan Data}

Metode pengumpulan data dalam penelitian ini adalalah Field Research dengan metode sebagai berikut:

1) Observasi

Hasil observasi lapangan dilakukan dengan pencatatan secara sistematik kejadian-kejadian, perilaku, objek-objek yang dilihat dan hal-hal lain yang diperlukan dalam mendukung penelitian yang sedang dilakukan. Teknik ini dengan menggunakan pengamatan langsung terhadap objek, yaitu langsung mengamati prosesi lamaran di Tomia yang dilaksanakan oleh masyarakat Tomia sendiri.

\section{2) Wawancara (Interview)}

Metode wawancara digunakan dalam penelitian ini merupakan pertemuan dua orang atau beberapa orang untuk bertukar informasi dan ide melalui tanya jawab, sehingga dapat dikonstruksikan makna dalam suatu topik tertentu. Jadi dengan teknik ini, peneliti melakukan wawancara langsung dengan pemuka adat atau sejumlah masyarakat baik secara individual atau kelompok. Peneliti sebagai interviewer bisa melakukan interview secara directive, dalam arti peneliti selalu berusaha mengarahkan topik pembicaraan sesuai dengan fokus permasalahan yang mau dipecahkan. Tujuannya yakni agar mendapatkan data yang semaksimal mungkin tentang tuturan atau ujaran lisan dalam lamaran pernikahan masyarakat di Tomia, Kabupaten Wakatobi.

\section{3) Catatan Lapangan}

Catatan lapangan merupakan teknik pengambilan data yang dilakukan melalui observasi yang digabungkan dengan interaksi dalam bentuk dialog dalam field penelitian secara partisipatoris. Melalui cara itu, peneliti diharapkan bisa memperoleh sejumlah data atas sebuah fokus permasalahan yang evidensinya diperoleh dari berbagai dimensi. Oleh karena itu, sebelum memasuki lapangan, peneliti harus bisa menetapkan tema yang dijadikan payung atas sejumlah fakta dan informasi yang ingin diperoleh.

\section{Teknik Analisis Data}

Penelitian kualitatif memungkinkan dilakukan analisis data pada waktu peneliti berada di lapangan maupun setelah kembali dari lapangan. Pada penelitian ini, analisis data dilaksanakan bersamaan dengan proses pengumpulan data. Adapun langkah-langkah analisis penelitian ini yakni tuturan dalam prosesi lamaran pernikahan di Tomia yang terdapat dalam rekaman diseleksi yang termasuk tuturan inti (isi) lamaran.

a) Pengklasifikasian data. Data hasil seleksi diidentifikasi berdasarkan pada fokus masalah, yakni wujud tuturan dalam prosesi lamaran pernikahan.

b) Penganalisisan Data. Data yang diklasifikasi, kemudian dianalisis dengan mendeskripsikan secara mendetail permasalahan yang terdapat dalam data yang telah dikumpulkan berdasarkan teori yang berkaitan sebagai dasar pedoman dalam menganalisis.

c) Penyimpulan Hasil Analisis. Penyimpulan terhadap semua fokus masalah (wujud kalimat dan makna) sebagai karakteristik tuturan dalam prosesi lamaran pernikahan di Tomia.

\section{PEMBAHASAN}


Hasil dalam penelitian ini menjawab pertanyaan dalam rumusan masalah, yakni wujud tuturan dalam prosesi lamaran pernikahan di Tomia dan makna tuturan dalam prosesi lamaran pernikahan di Tomia yang dilakukan melalui wawancara dengan beberapa informan. Wujud tuturan dalam penelitian ini berfokus pada tuturan atau ujaran dalam tataran kalimat.

\section{Wujud Tuturan dalam Prosesi Lamaran Pernikahan di Tomia}

Hasil penelitian menunjukkan bahwa tahapan dalam lamaran pernikahan di Tomia terdiri atas empat wujud tahapan. Keempat tahapan itu meliputi Pa'epe, Pa'rara, Po'ema-ema, dan Nga'a Nualo.

\section{a. Wujud Tuturan dalam Tahap Pa'epe}

Perwujudan $P a$ 'epe dalam prosesi lamaran, yakni pihak laki-laki yang bermaksud melamar pihak perempuan akan mengutus dua atau tiga orang perempuan (orang tua). Pertemuan tersebut bersifat rahasia guna menghindari hal-hal yang dapat menggagalkan rencana pelamaran atau rencana pernikahan.

Isi pembicaraan dalam pertemuan tersebut untuk memberikan informasi kepada pihak keluarga perempuan perihal akan ada yang datang ke rumah pihak perempuan. Penunjukan dua atau tiga orang perempuan dalam wujud $P a$ 'epe ini memiliki maksud tertentu, yakni karena di Wakatobi khususnya di Tomia para ibu-ibu rumah tangga sebuah kebiasaan mereka bertandang ke rumah-rumah tetangga sehingga dengan peran ibu-ibu tersebut dalam wujud ini, wujud Pa'epe terkesan rahasia.

Adapun tuturan dalam tahap $P a$ 'epe, yakni

Asslamu alaikum. Asslamu alaikum. Asslamu alaikum warahmatullahi wabarakatuh.

Na'e terekeno na'ana tohalangiemo nakarja'amiu dahani.
Jari fa'a koratongkita ana. Anne'e kene paralu mammi kassapo ana

Ilange utu anne'e na'atu kene mansuana ako temai nototolu. Jari tamo'oli mococo ako teilange utu atu.

Ara afana'atu kaposangamo pida la'amo kufa'e natumudukkami ana kua topococo ako tealo.

Assalamu alaikum warahmatullahi wabarakatuh.

Tuturan-tuturan di atas termasuk tuturan yang berada pada lamaran pernikahan adat Tomia dalam tahap Pa'epe. Wujud-wujud linguistik dalam tuturan ini akan dilihat wujud kalimatnya. Wujud kalimat yang terdapat dalam tahap Pa'epe meliputi kalimat deklaratif dan kalimat interogatif. Berikut contoh datanya.

a. Wujud Kalimat Deklaratif

(1) Asslamu alaikum. Asslamu alaikum. Asslamu alaikum warahmatullahi wabarakatuh. (Salam pembuka.)

(2) Na'e terekeno na'ana tohalangi emo nakaraja miu dahani.

(Kedatangan kami, mungkin menghambat aktivitas kalian.)

(3) Jari fa'a koratongkita ana. Anne'e kene paralu mammi kassapo ana. (Jadi kami datang ini, ada maksud dengan orang yang ada di rumah ini.)

(4) Ilange utu anne'e na'atu kene mansuana ako temai nototolu.

(Besok malam itu akan ada yang bertandang, yaitu tiga orang.)

(5) Ara afana atu kaposangamo pida la'amo kufae natumudukkami ana kua topococo ako tealo.

(Kalau seperti itu, kami pamit nanti kami informasikan kepada keluarga yang di rumah bahwa pertemuan disepakati besok malam.)

(6) Assalamu alaikum warahmatullahi wabarakatuh.

(Salam penutup.) 
b. Wujud Kalimat Interogatif

(1) Jari tamo'oli mococo ako teilange utu atu?

(Jadi apakah ada kesiapan kita untuk besok malam itu?)

\section{b. Wujud Tuturan dalam Tahap Pa'rara}

Wujud Pa'rara akan terlaksana jika ada jawaban persetujuan dari pihak keluarga perempuan melalui proses wujud Pa'epe. Pihak yang berperan atau yang akan diutus dalam wujud ini adalah dua atau tiga orang tua laki-laki untuk bertandang ke rumah pihak keluarga perempuan. Pemilihan dua atau tiga orang tua laki-laki dengan maksud bahwa wujud Pa'rara sudah merupakan tahapan yang tidak bersifat rahasia lagi. Artinya, para tetangga sudah dapat mengetahui tujuan atau maksud yang akan dituju oleh pihak laki-laki.

Isi pembicaraan dalam pertemuan tersebut perihal menanyakan status si perempuan (ada tidaknya laki-laki yang sudah datang melamar) dari perempuan yang akan dilamar nanti.

Adapun tuturan dalam tahap

Pa'rara, yakni

Assalamu alaikum. Assalaamu alaikum.

Assalamu alaikum warahmatullahi wabarakatuh.

Terekeno baba'anngkitamo namansuana

$i$ elloto? Meammo na'iheta'o. Sukur alhamdullah.

Jari $i$ lalo nuratongkita ana kasumussulumo temansuana di tudu $i$ nggafi. Jari kuratonggkita ana notudukkami i La Abudulu ako teanano $i$ La Masilani berupa nguru ka u'mema nguru terekeno na ananto $i$ sapo ana ka'iho topoinepe'e kua meaho nasangkutano kene kene atafa meaho narumanggkamie.

I La Masilani ana anne'e kene hitara'a moina ka ananto ana berupa moina nomoina nahitara'anno na ana imai akommami ana ka hotoana i sapo ana. Jari kamelumo na'ana temoina nuhitira'anto babangkita. Jari anne'e naintenga?
Tarima kasi baba'angkita atuna'emmo anne'a ka'amea naintenga kuratongkita ana dika'ane ko'ammala kua mudamudaha telakommami ana nohukkita ala'a te'intenga ndumeu brupa nu intenga ka'i nohofoso.

Jari ara meaho nasangkutano atafa meaho narumanggkamie, sukur alhamdulillah.

Ara afana atu kamosangamo. Nggala dia kapumaratonne $k a$ mansuana tumudukkami ana kua anne'a ka'amea na intenga. Assalamu alaikum.

Tuturan-tuturan di atas termasuk tuturan yang berada pada lamaran pernikahan adat Tomia dalam tahap Pa'rara. Wujud-wujud linguistik dalam tuturan ini akan dilihat wujud kalimatnya. Wujud kalimat yang terdapat dalam tahap Pa'rara meliputi kalimat deklaratif dan kalimat interogatif. Berikut contoh datanya.

\section{a. Wujud Kalimat Deklaratif}

(1) Assaalamu alaikum. Assalamu alaikum. Assalamu alaikum warahmatullahi wabarakatuh. (Salam pembuka.)

(2) Sukur alhamdullah. (Sukur alhamdulillah.)

(3) Jari ilalo nuratongkita ana kasumussulumo temansuana itudu inggafi.

(Jadi maksud kami datang ini untuk menindaklanjuti kesepakatan orang tua yang bertandang kemarin.)

(4) I La Masilani ana anne'e kene hitara'a moina $k a$ ananto ana berupa moina nomoina nahitara'anno na'ana imaiakommami ana ka hotoana $i$ sapo ana.

(La Maslani ini ada persaan terang. Terang ini brupa rasa suka terhadap anak di rumah ini.)

(5) Tarima kasi baba'angkita atuna'emmo anne'a ka'amea naintenga kuratongkita ana dika'ane ko'ammala kua muda- 
mudaha telakommami ana nohukkita ala'a te'intenga ndumeu brupa nu intenga ka'i nohofoso.

(Terima kasih untuk dibukakannya jalan untuk kami untuk bersatu dengan keluarga ini, sebelum kami datang tadi kami berdoa mudamudahan keluarga perempuan memberi kita jalan yang tidak berumput/berliku.)

(6) Jari ara meaho nasangkutano atafa meaho narumanggkamie, sukur alhamdulillah.

(Jadi kalau belum ada yang memasang duri/memagari hati si perempuan di rumah ini, syukur alhamdulillah.)

(7) Ara afana atu kamosangamo. Nggala dia kapumaratonne $k a$ mansuana tumudukkami ana kua anne'a ka'amea na intenga. Assalamu alaikum.

(Jadi kalau begitu kami pamit supaya kami menginformasikan kepada orang tua laki-laki yang menyuruh kami bahwa ada jalan.

\section{b. Wujud Kalimat Interogatif}

(1) Terekeno baba'anngkitamo namansuana di elloto? Meammo na iheta'o?

(Sudah semua orang kita yang di undang? Apakah sudah tidak ada lagi yang kita tunggu?)

(2) Jari kuratonggkita ana notudukkami i La Abudulu ako teanano $i$ La Masilani berupa nguru ka u'mema nguru terekeno na ananto $i$ sapo ana ka'iho topoinepe'e kua meaho nasangkutano kene kene atafa meaho narumanggkamie.

(Jadi kedatangan kami ini diamanahkan oleh La Abudulu untuk anaknya bernama La Masilani berupa kabar apakah sudah ada yang pernah datang ke rumah ini sebelum kami?)
(3) Jari kamelumo na'ana temoina nuhitira'anto babangkita. Jari anne'e naintenga?

(Jadi kami meminta kebesaran hati kita semua, apakah ada jalan?)

\section{c. Wujud Tuturan dalam Tahap Po'ema-ema}

Wujud Po'ema-ema akan terlaksana jika sudah ada informasi dari pihak peremuan mengenai hasil dari wujud Pa'rara, yaitu perihal akan diterimanya pihak laki-laki tersebut jika pengakuan dari pihak keluarga perempuan mengenai belum ada yang datang melamar si perempuan, maka akan dilanjutkan ke tahap selanjutnya, yakni tahapan Po'emaema. Sebaliknya akan ditolaknya pihak laki-laki, jika pengakuan dari pihak keluarga perempuan tentang sudah adanya pihak laki-laki lain yang sudah melamar sehingga tahapan hanyalah sampai pada wujud Po Rara.

Tujuan inti wujud Po'ema-ema, yaitu menyatukan kesepakatan kedua belah pihak (pihak keluarga laki-laki dan pihak keluarga perempuan) perihal mahar yang akan dibebankan kepada pihak laki-laki misalnya satu set emas atau uang tunai. Namun, dalam pertemuan ini diwajibkan bagi pihak laki-laki membawa satu cincin emas yang harus diterima oleh pihak perempuan. Cincin emas tersebut sebagai bukti terikatnya hubungan mereka untuk menuju ke jenjang pernikahan.

Adapun tuturan dalam tahap Po'emaema, yakni

Sebelum kupahenna'ue nahengga nukkindu mami ka tonga nu'asa-asanto. Ma'afu akonsami. Kene temai akommami ana temoina, inta tamo'ahae ni kita mannusia ana nobukekkami tesumala. Bara nohekeda'o tekkindu mami kene tade mammi kene bara nohikida'o namoina imai akommammi ana. Na'e kurantonggkitamo uka. Tarima kasi tahumoja akomo te ihoja akonto di hua. Kuratongkita ana 
kamatottida ako teilemba atafa ako tediturumba mami kua moha umpa.

Sukur alhamdulillah. Boha atu uka nahefinalutikkami mina $i$ sapo. Jari tamogaumo ako te'atu nggala ia telangketo to 'afa ala'a temoluha.

Ara afana atuna, kamosangamo.

Assalamu alaikum warahmatullahi wabarakatuh.

Tuturan-tuturan di atas termasuk tuturan yang berada pada lamaran pernikahan adat Tomia dalam tahap Po'ema-ema. Wujud-wujud linguistik dalam tuturan ini akan dilihat wujud kalimatnya. Wujud kalimat yang terdapat dalam tahap Po'ema-ema meliputi kalimat deklaratif, kalimat interogatif, dan kalimat imperatif. Berikut contoh datanya.

a. Wujud Kalimat Deklaratif

(1) Sebelum kupahenna'ue nahengga nukkindu mami ka tonga nu'asaasanto.

(Sebelum kami menurunkan maksud dan tujuan kami ke Majelis Adat.)

(2) Kene temai akommami ana temoina, inta tamo'ahae ni kita mannusia ana nobukekkami tesumala.

(Kedatangan kami ini dengan hati yang terang [bersih] namun kita manusia tidak luput dari khilaf.)

(3) Bara nohekeda'o tekkindu mami kene tade mammi kene bara nohikida'o namoina imai akommammi ana.

(Jangan sampai sikap dan perbuatan kami merusak niat awal kami.)

(4) Na'e kurantonggkitamo uka. Tarima kasi tahumoja akomo te ihoja akonto di hua.

(Ini kami tiba kembali lagi terima kasih kita akan kembali membicarakan maksud dan tujuan yang kita birakan pada kedatangan kami kemarin.)

(5) Sukur alhamdulillah. (Syukur alhamdulillah.)
(6) Boha atu uka nahefinalutikkami mina i sapo.

(Seberat itu juga bekal yang kami siapkan dari rumah.)

b. Wujud Kalimat Interogatif

(1) Kuratongkita ana kamatottida ako teilemba atafa ako tediturumba mami kua moha umpa.

(Perihal yang akan kami pikul atau yang akan kami junjung, kira-kira sebesar apa.)

(2) Jari tamogaumo ako te'atu nggala ia telangketo to'afa ala' 'a temoluha. (Jadi, itulah yang kita sepakati supaya kita bisa melaksanakan hajat kita dengan baik.)

c. Wujud Kalimat Imperatif

(1) Ma'afu akonsami.

(Kami minta maaf terlebih dahulu.)

\section{d. Wujud Tahapan Nga'a Nualo}

Nga'a Nualo adalah wujud tahapan pernikahan setelah terlaksananya wujud Po'ema-ema. Wujud ini bisa dilaksanakan bersamaan dengan wujud Po'ema-ema dan bisa berjarak beberapa minggu atau bulan bahkan tahunan setelah wujud Po'emaema. Inti dari wujud Nga'a Nualo ini pihak laki-laki dan pihak perempuan menyepakati waktu untuk melangsungkan prosesi pernikahan. Setelah adanya kesepakatan waktu oleh kedua belah pihak, maka kewajiban bagi kedua belah pihak untuk mempersiapkan segala hal yang menyangkut pernikahan si pihak laki-laki dan si pihak perempuan.

Adapun tuturan dalam tahap $\mathrm{Nga} a$ Nualo, yakni

Assalamu alaikum. Assalamu alaikum.

Assalamu alaikum warahmatullahi wabarakatuh.

Pale-pale nahoja na'e topo'afamo uka tehenggano norekomo na'ako te'ilemba kene ako te'iturumba mami. Jari tahumoja akomo telangketo kira-kira ialo mi'umpa mia talumangke ta'umafa temoluha kene mellai kene rifu. 
Nggala dia tolangke torato afana uka kene.

Sukur alhamdulillah atuna'e tamogaunnako temoina nuhammisi natalumangke. Temoina mia'atu nondeu na'alo. Atuna'e norekomo nahoja ara afana atuna kamosangamo nggala dia kapadahani'e na'ammai sapo kua telangkea imoina nuhammisi.

Assalamu alaikum.

Tuturan-tuturan di atas termasuk tuturan yang berada pada lamaran pernikahan adat Tomia dalam tahap Nga'a Nualo. Wujud-wujud linguistik dalam tuturan ini akan dilihat wujud kalimatnya. Wujud kalimat yang terdapat dalam tahap Nga'a Nualo meliputi kalimat deklaratif dan kalimat imperatif. Berikut contoh datanya.

a. Wujud Kalimat Deklaratif (1) Assalamu alaikum. Assalamu
alaikum. Assalamu alaikum
warahmatullahi wabarakatuh. (Salam pembuka.)

(2) Pale-pale nahoja na'e topo'afamo uka tehenggano norekomo na'ako te'ilemba kene ako te'iturumba mami.

(Sudah cukup basa-basinya kita, sekarang kita bertemu kembali dan ini sudah jelas yang akan kami pikul dan yang akan kami jinjing.)

(3) Nggala dia tolangke torato afana uka kene.

(Supaya kita berangkat dan tiba seperti orang lain juga.)

(4) Sukur alhamdulillah atuna'e tamogaunnako temoina nuhammisi natalumangke.

(Syukur alhamdulillah itu sudah kesepakatan kita bahwa hari Kamis adalah hari keberangkatannya kita.)

(5) Temoina mia'atu nondeu na'alo. (Hari itu adalah hari yang baik.)

(6) Atuna'e norekomo nahoja ara afana atuna kamosangamo nggala dia kapadahani'e naammai sapo kua telangkea imoina nuhammisi.
(Itu sudah cukup yang kita bicarakan, kami pamit agar kami dapat memberitahukan orang rumah bahwa hari Kamis adalah hari keberangkatan kita.)

b. Wujud Kalimat Imperatif

(1) Jari tahumoja akomo telangketo kira-kira ialo mi'umpa mia talumangke ta'umafa temoluha kene mellai kene rifu.

(Jadi kita bicarakan lagi mengenai kapan kita akan berangkat, kira-kira hari apa yang baik agar kita dalam perjalanan nanti mendapat cuaca yang teduh dan dijauhkan dari cuaca yang buruk.)

\section{Makna Tuturan dalam Prosesi Lamaran Pernikahan di Tomia}

Setelah rumusan masalah pertama terjawab, maka selanjutnya masuk pada rumusan kedua, yakni memaknai tuturan dalam prosesi lamaran pernikahan di Tomia dengan berdasar pada lima tahapan lamaran, yakni Pa'epe, Pa'rara, Po'emaema, Nga'a Nualo

\section{a. Makna Tuturan dalam Tahap Pa'epe}

Makna Pa'epe secara leksikal adalah terdiri dari dua kata, yakni pa dan epe. Kata pa berarti pelaku atau orang sedangkan kata epe berarti efek. Secara harfiah arti dari frasa $P a$ 'epe pelaku atau orang yang memberikan suatu efek/tanda kepada pihak lain. Dilihat dari konteks prosesi pernikahan maksud atau makna Pa'epe adalah adanya utusan berupa orang tua perempuan yang berjumlah dua atau tiga orang dari pihak keluarga laki-laki ke pihak keluarga perempuan untuk memberikan tanda bahwa akan ada yang datang bertandang nanti.

Adapun tuturan dalam tahap $P a$ 'epe, yakni

Assalamu alaikum. Assalamu alaikum. Assalamu alaikum warahmatullahi wabarakatuh.

(Kalimat salam.) 
Tuturan pembuka di atas dituturkan oleh utusan keluarga pihak laki-laki kepada keluarga pihak perempuan. Salam pembuka dituturkan untuk memberi salam. Di Tomia, masyarakatnya seratus persen memeluk agama Islam sehingga pelaksanaan adat-adat khususnya prosesi lamaran disisipkan dengan ajaran agama Islam.

Tuturan salam yang diucapkan oleh keluarga pihak laki-laki tersebut dituturkan sebanyak tiga kali kepada keluarga pihak perempuan. Makna dari tuturan ini adalah penggambaran kunjungan dengan rasa hormat dan menghargai keluarga pihak laki-laki kepada keluarga pihak perempuan. Tuturan salam yang diucapkan sebanyak tiga kali berturut-turut bermakna memperlihatkan keseriusan maksud atau tujuan atas kunjungan keluarga pihak lakilaki ke keluarga pihak perempuan.

$\mathrm{Na}$ 'e terekeno na'ana tohalangiemo nakarjamiu dahani.

(Mungkin kedatangan kami menghambat aktivitas kalian.)

Tuturan di atas bertujuan menginformasikan maksud kedatangan pihak keluarga laki-laki kepada pihak keluarga perempuan. Tuturan tersebut merupakan tuturan yang mengandung maksud menawarkan suatu maksud atau tujuan kedatangan mereka. Tuturan yang diucapkan oleh pihak keluarga laki-laki tersebut berada pada posisi bawah, karena yang berkuasa atas persetujuan terhadap maksud itu adalah pihak keluarga perempuan.

Jari fa'a kuratongkita ana, anne kene paralu mami kasapo ana.

(Jadi, kami tiba ini, ada maksud dengan orang yang ada di rumah ini.)

Tuturan di atas bertujuan menjelaskan maksud kedatangan pihak keluarga laki-laki yang di tujukan langsung kepada pihak perempuan. Maksud dari tuturan tersebut memberitahukan langsung tujuan kedatangan mereka kepada pihak keluarga perempuan tersebut tentang niat mereka.
I lange utu anne'e na'atu kene mansuana ako temai no totolu.

(Besok malam akan ada yang bertandang, yaitu tiga orang tua.)

Tuturan di atas bermaksud memberitahukan bahwa akan ada orang tua laki-laki dari pihak keluarga laki-laki yang akan bertandang atau berkunjung besok malam dengan maksud atau niat yang sama dengan maksud kedatangan hari ini.

Jari tamooli mococo ako te ilange utu atu...

(Jadi apakah ada kesiapan kalian untuk besok malam nanti.)

Tuturan di atas bertujuan menanyakan perihal kesepakatan dan kesiapan pihak keluarga perempuan untuk kesiapan mereka menerima kedatangan pihak keluarga laki-laki besok malam.

Ara afana atu kaposangamo pida laamo ku faae na tumudukkami ana kua topococo akao te alo.

(Kalau seperti itu, kami pamit nanti kami informasikan kepada keluarga yang di rumah bahwa pertemuan disepakati besok malam.)

Tuturan tersebut bermaksud memberitahukan kepada pihak keluarga perempuan bahwa penentuan hari untuk besok telah disepakati dan kesepakatan ini akan langsung diinformasikan kepada pihak keluarga laki-laki.

Assalamu alaikum warahmatullahi wabarakatuh.

(Kalimat penutup, yakni salam)

Tuturan di atas ditutup dengan pemberian salam. Maksud tuturan tersebut adalah untuk menutup agenda pokok pembicaran terhadap maksud dan tujuan pihak keluarga laki-laki kepada pihak keluarga perempuan.

\section{b. Makna Tuturan dalam Tahap Pa'rara}

Makna Pa'rara secara leksikal adalah terdiri dari dua kata, yakni $P a$ dan Epe. Kata $P a$ berarti pelaku atau orang sedangkan kata Rara berarti tranparansi. Secara harfiah arti dari frasa Pa'rara adalah pelaku atau orang yang memberikan 
keadaan transparansi mengenai adanya keinginan pihak keluarga laki-laki yang ingin melamar pihak keluarga perempuan. Pihak yang berperan atau yang akan diutus dalam wujud ini adalah dua atau tiga orang tua laki-laki untuk bertandang ke rumah pihak keluarga perempuan.

Adapun tuturan dalam tahap
Pa'rara, yakni
Assalamu alaikum. Assalamu alaikum.
Assalmu alaikum warahmatullahi
wabarakatuh.
(Kalimat salam.)
Tuturan pembuka di atas dituturkan
oleh utusan keluarga pihak laki-laki kepada keluarga pihak perempuan. Salam pembuka dituturkan untuk memberi salam. Di Tomia, masyarakatnya seratus persen memeluk agama Islam sehingga pelaksanaan adat-adat khususnya prosesi lamaran disisipkan dengan ajaran agama Islam.

Tuturan salam yang diucapkan oleh keluarga pihak laki-laki tersebut dituturkan sebanyak tiga kali kepada keluarga pihak perempuan. Makna dari tuturan ini adalah penggambaran kunjungan dengan rasa hormat dan menghargai keluarga pihak laki-laki kepada keluarga pihak perempuan. Tuturan salam yang diucapkan sebanyak tiga kali berturut-turut bermakna memperlihatkan keseriusan maksud atau tujuan atas kunjungan keluarga pihak lakilaki ke keluarga pihak perempuan.

Terekeno baba'anngkitamo namansuana di elloto. Meammo na iheta'o. Sukur alhamdullah. Meammo naiheta'o. Sukur alhamdulillah.

(Sudah semua orang tua yang diundang? Apakah sudah tidak ada lagi yang kita tunggu?)

Tuturan tersebut bermaksud menanyakan kepada pihak keluarga perempuan oleh pihak keluarga laki-laki perihal tamu-tamu yang sudah hadir dalam pertemuan tersebut.
Jari $i$ lalo nuratongkita ana kasumussulumo temansuana di tudu inggafi.

(Jadi maksud kami datang ini untuk menindaklanjuti kesepakatan orang tua yang bertandang kemarin.)

Tuturan di atas bermaksud menanyakan tindak lanjut yang telah disepakati oleh kedua belah pihak keluarga yang diutus oleh pihak keluarga laki-laki sebelumnya.

Jari kuratonggkita ana notudukkami $i$ La Abudulu ako teanano i La Masilani berupa nguru ka u'mema nguru terekeno na ananto $i$ sapo ana ka'iho topoinepe'e kua meaho nasangkutano kene kene atafa meaho narumanggkamie.

(Jadi kedatangan kami ini diamanahkan oleh La Abudulu untuk anaknya bernama La Masilani berupa kabar apakah sudah ada yang pernah datang ke rumah ini sebelum kami.)

Tuturan di atas bermaksud menjelaskan kedatangan orang tua yang diutus oleh pihak keluarga laki-laki dalam hal ini orang tua tersebut datang karena diamanahkan oleh La Abudulu selaku orang tua/bapak dari calon mempelai lakilaki yang bernama La Masilani, bahwa apakah sudah ada orang lain yang pernah datang melamar si gadis yang ada di rumah tersebut.

I La Masilani ana anne'e kene hitara'a moina ka ananto ana berupa moina nomoina nahitara'anno na'ana imaikommami ana kahotoana $i$ sapo ana.

(La Maslani ini selalu mengingat setiap waktu kepada anak gadis kita berupa hari demi hari ingatannya tentang gadis di rumah ini.)

Tuturan tersebut bermakna bahwa orang tua yang diutus tersebut menjelaskan kepada pihak keluarga perempuan perihal La Masilani (selaku pihak laki-laki) mempunyai perasaan cinta kepada anak perempuan yang dimaksud. 
Totobuang, Vol. 6, No. 2, Desember 2018: 183-199

Jari kamelumo na'ana temoina nuhitira'anto babaangkita. Jari anne'e na'intenga?

(Jadi kami meminta kebesaran hati kita semua, apakah ada jalan?)

Tuturan di atas bermakna meminta persetujuan dengan sungguh-sungguh perihal adakah jalan untuk bisa menyatukan mereka (pihak laki-laki dan pihak perempuan) dalam ikatan yang lebih serius.

Tarima kasi baba'angkita atuna'emmo anne'e ka'amea naintenga kuratongkita ana dika'ane koammala kua mudamudaha telakommami ana nohukkita ala'a teintenga ndumeu brupa nu'intenga ka'i nohofoso.

(Terima kasih untuk diberikannya jalan kepada kami untuk bersatu dengan keluarga ini, sebelum kami datang tadi berdoa mudah-mudahan keluarga perempuan memberi kita jalan yang baik berupa jalan yang tidak berumput/berliku.)

Tuturan di atas bermakna ucapan terima kasih pihak keluarga laki-laki kepada pihak keluarga perempuan atas diberikannya suatu jalan keluar, yakni berupa disetujuinya suatu hubungan yang akan dijalani oleh pihak laki-laki dan pihak perempuan untuk bersatu menjadi sebuah keluarga. Tak lupa pula sebelum pihak keluarga laki-laki bertandang ke rumah pihak keluarga perempuan, mereka berdoa agar pihak keluarga perempuan dapat merestui dan tidak memberikan halangan terhadap hubungan kedua pihak tersebut.

$$
\begin{aligned}
& \text { Jari ara meaho nasangkutano atafa } \\
& \text { meaho narumanggkamie sukur }
\end{aligned}
$$
alhamdulillah.

(Jadi kalau belum ada yang memasang duri [memagari hati si perempuan] di rumah ini, sukur alhamdulillah.)

Tuturan di atas bermakna rasa syukur pihak keluarga laki-laki atas pengakuan dari pihak keluarga perempuan perihal belum adanya laki-laki lain yang datang melamar gadis tersebut.
Ara afana'atu kamosangamo nggala dia kapumaratonne $k a$ mansuana tumudukkami ana kua anne ka'amea naintenga.

(Kalau begitu kami pamit dulu agar kami menginformasikan kepada orang tua laki-laki yang menyuruh kami bahwa ada jalan.)

Tuturan di atas bermakna pihak keluarga laki-laki berpamitan untuk pulang dari rumah pihak keluarga perempuan dan akan memberitahukan kabar gembira kepada orang tua pihak laki-laki tentang hasil kesepakatan kedua pihak keluarga bahwa pihak keluarga perempuan memberikan restu atas hubungan kedua pihak tersebut.

Assalamu alaikum.

(Salam penutup.)

\section{c. Makna Tuturan dalam Tahap Po'ema-ema}

Makna Po'ema-ema secara leksikal adalah terdiri dari dua kata, yakni po dan ema-ema. Kata po berarti saling sedangkan kata ema-ema merupakan bentuk reduplikasi yang berarti berdiskusi. Secara harfiah arti dari frasa Po'ema-ema adalah saling berdiskusi antara kedua belah pihak. Dilihat dari konteks prosesi pernikahan maksud atau makna Po'ema-ema adalah adanya kegiatan saling berdiskusi antar kedua belah pihak (pihak keluarga laki-laki dengan pihak keluarga perempuan) mengenai mahar yang akan dibayar oleh pihak keluarga laki-laki.

Adapun tuturan dalam tahap Po'emaema, yakni

Assalamu alaikum. Assalamu alaikum. Assalamu alaikum warahmatullahi wabarakatuh.

(Salam pembuka.)

Sebelum kupahenna'ue nahengga nukkindu mami ka tonga nu'asa-asanto, maafu akonsami.

(Sebelum kami menurunkan maksud dan tujuan kami ke Majelis Adat, kami minta maaf terlebih dahulu.) 
Tuturan di atas bermaksud menyampaikan permohonan maaf kepada pihak keluarga perempuan, sebelum perihal maksud dan tujuan pihak keluarga laki-laki ke Majelis Adat. Permohonan maaf tersebut bertujuan ingin memperlihatkan rasa hormat dan segannya pihak keluarga laki-laki kepada pihak keluarga perempuan.

Kene temai akommami ana temoina inta tamo'ahae nikita mannusia ana nobukekkami tesumala.

(Kedatangan kami ini dengan hati yang terang/bersih namun kita manusia tidak luput dari khilaf.)

Tuturan tersebut bertujuan menampakkan kerendahan hati pihak keluarga laki-laki kepada pihak keluarga perempuan. Tuturan ini bermaksud bahwa apapun sikap dan perbuatan yang telah kami perlihatkan selama ini, karena mereka hanyalah manusia yang tidak pernah luput dari salah. Namun, kedatangan mereka benar-benar terbuka, bersih dari maksud dan tujuan negatif.

Bara nohekeda'o tekkindu mami kene tade mammi kene bara nohikida'o namoina imai akommammi ana.

(Jangan sampai sikap dan perbuatan kami merusak niat awal kami.)

Tuturan tersebut bermaksud menyampaikan kepada pihak keluarga perempuan bahwa kedatangan pihak keluarga laki-laki tersebut terbuka, artinya jangan karena ada kesalahan yang telah diperbuat pada masa silam, sehingga memperkeruh atau menjadi hambatan terhadap maksud dan tujuan kedatangan mereka.

Na'e kurantonggkitamo uka.

(Ini kami tiba kembali lagi.)

Tuturan tersebut bermaksud memberitahukan kepada pihak keluarga perempuan bahwa pihak keluarga laki-laki datang lagi kembali ingin menanyakan perihal maksud dan tujuan mereka sebelumnya.

Tarima kasi tahumoja akomo te dihoja akonto di hua.
(Terima kasih kita akan kembali mencandakan maksud dan tujuan yang kita candakan pada kedatangan kami dua hari yang lalu.)

Tuturan tersebut bermaksud membicarakan kembali perihal maksud dan tujuan yang telah mereka bicarakan pada pertemuan mereka sebelumnya.

Kuratongkita ana kamatottida ako te'ilemba atafa ako tediturumba mami kua boha umpa.

(Kami tiba ini kami ingin memperjelas perihal yang akan kami pikul atau yang akan kami junjung, kira-kira sebesar apa.)

Tuturan di atas bermaksud ingin memberitahukan dan menanyakan kepada pihak keluarga perempuan perihal kejelasan tentang mahar yang akan dibebankan kepada pihak keluarga lakilaki.

Sukur alhamdulillah boha atu uka nahefinalutikkami mina di sapo.

(Syukur alhamdulillah, seberat itu juga bekal yang kami siapkan dari rumah.)

Tuturan di atas ingin menyampaikan atau menginformasikan kepada pihak keluarga laki-laki bahwa beban yang mereka saratkan kepada pihak keluarga laki-laki sudah mereka siapkan dari rumah.

Jari tamogaumo ako te'atu nggaladia telangketo to'afa alaa temoluha.

(Jadi, itulah yang kita sepakati supaya kita bisa melaksanakan hajat kita dengan baik.)

Tuturan tersebut bermaksud menginformasikan bahwa sudah adanya kesepakatan antara kedua pihak keluarga perihal akan dilaksanakannya hajat atau maksud yang mereka sepakati bersama.

Ara afana atuna kamosangamo.

(Kalau begitu kami pamit.)

Tuturan tersebut bermaksud untuk memberitahukan kepada pihak keluarga laki-laki untuk berpamitan dari pertemuan tersebut.

Assalamu alaikum warahmatullahi wabarakatuh. 
(Kalimat salam penutup.)

Tuturan di atas ditutup dengan pemberian salam. Maksud tuturan tersebut adalah untuk menutup agenda pokok pembicaran terhadap maksud dan tujuan pihak keluarga laki-laki kepada pihak keluarga perempuan.

\section{d. Makna Tuturan dalam Tahap Nga'a Nualo}

Makna Nga'a Nualo secara leksikal adalah terdiri dari tiga kata, yakni $n g a, n u$, dan alo. Kata nga berarti penamaan, kata $n u$ berarti -nya (kepunyaan), sedangkan kata alo berarti hari. Secara harfiah arti dari frasa Nga'a Nualo adalah penamaan (penentuan) nama hari. Dilihat dari konteks prosesi pernikahan maksud atau makna Nga'a Nualo adalah penentuan waktu pernikahan oleh kedua belah keluarga (keluarga pihak laki-laki dengan keluarga pihak perempuan).

Adapun tuturan dalam tahap $\mathrm{Nga}^{\prime} a$ Nualo, yakni

Assalamu alaikum. Assalamu alaikum. Asslamu alaikum warahmatullahi wabarakatuh.

(Kalimat salam.)

Tuturan pembuka di atas dituturkan oleh utusan keluarga pihak laki-laki kepada keluarga pihak perempuan. Salam pembuka dituturkan untuk memberi salam. Di Tomia, masyarakatnya seratus persen memeluk agama Islam sehingga pelaksanaan adat-adat khususnya prosesi lamaran disisipkan dengan ajaran agama Islam.

Pale-pale nahoja na'e topo'afamo uka tehenggano norekomo na'ako te'ilemba kene ako te diturumba mami.

(Sudah cukup basa-basinya kita, sekarang kita bertemu kembali dan ini sudah jelas yang akan kami pikul dan yang akan kami jinjing.)

Tuturan di atas bermakna bahwa semua hal yang telah dibicarakan pada pertemuan tiap tahapan sebelumnya sudah dicukupkan, sekarang dipertemukan kembali dan ini sudah jelas mahar yang dibebankan kepada pihak keluarga lakilaki.

Jari tahumoja akomo telangketo kirakira $i$ alo miumpa mia talumangke ta'umafa temoluha kene mellai kene rifu. (Jadi kita bicarakan lagi mengenai kapan kita akan berangkat, kira-kira hari apa yang baik agar kita dalam perjalanan nanti mendapat cuaca yang teduh dan dijauhkan dari cuaca yang buruk.)

Tuturan di atas bermakna tentang penentuan waktu pernikahan, kapan hari baik akan melangsungkan pernikahan agar dalam berlangsungnya pernikahan tidak mendapat keberkahan (berjalan lancar) dan tidak mendapatkan hambatan di tengah acara pernikahan nanti.

Nggala dia tolangke torato afana uka kene.

(Supaya kita berangkat dan tiba seperti orang lain juga.)

Tuturan di atas bermakna agar persiapan pernikahan yang akan dilangsungkan tersebut berjalan lancar seperti orang lain juga.

Sukur alhamdulillah atuna'e tamogaunnako temoina nuhammisi natalumangke.

(Syukur alhamdulillah itu sudah kesepakatan kita bahwa hari Kamis adalah hari keberangkatannya kita.)

Tuturan di atas bermakna rasa syukur antara kedua pihak keluarga terhadap hari baik yang telah mereka sepakati bersama untuk melangsungkan acara pernikahan anak-anak mereka.

Temoina mia'atu nondeu na'alo.

(Hari itu adalah hari yang baik.)

Tuturan di atas bermakna bahwa hari yang telah disepakati tersebut merupakan hari yang baik untuk melangsungkan acara pernikahan putra dan putri mereka.

Atuna'e norekomo nahoja ara afana atuna kamosangamo nggala dia kapadahani'e na'ammai sapo kua telangke'a imoina nuhammisi. 
(Itu sudah cukup yang kita bicarakan, kami pamit agar kami dapat memberitahukan orang rumah bahwa hari Kamis adalah hari keberangkatan kita.)

Tuturan di atas bermakna mencukupkan sudah pembahasan atau kesepakatan akhir pada pertemuan tersebut. Pihak keluarga laki-laki berpamitan agar dapat memberitahukan kabar tersebut kepada keluarga besar pihak keluarga lakilaki bahwa acara pernikahan yang telah disepakati adalah hari Kamis.

Assalamu alaikum.

(Salam penutup.)

\section{PENUTUP}

Berdasarkan rumusan masalah yang telah terjawab dalam bagian pembahasan maka dapat disimpulkan bahwa bentuk tahapan dalam proses lamaran di Tomia terdiri atas empat bentuk. 1) Pa'epe. 2) Pa'rara; 3) Po'ema-ema dan 4) Nga'a Nualo. Dari keempat bentuk prosesi lamaran tersebut tuturan yang dituturkan bervariasi. Pada bentuk Pa'epe, Pa'rara, dan Nga'a Nualo wujud tuturannya berbentuk deklaratif dan interogatif. Sementara pada tahapan Po'ema-ema wujud tuturannya berbentuk deklaratif, imperatif dan interogatif.

Makna dalam tuturan prosesi lamaran bermakna konotasi karena mempunyai nilai rasa yang tinggi untuk menyampaikan maksud dan tujuan dalam tuturan prosesi lamaran pernikahan di Tomia. Fungsi makna konotasi, dalam tuturan prosesi lamaran pernikahan di Tomia bertujuan memperhalus tuturan.

\section{DAFTAR PUSTAKA}

Hasan, M. Ali. 2006. Pedoman Hidup Berumah Tangga dalam Islam. Jakarta: Prenada Media Group.

Nuruddin, Amiur dan Azhari Akmal Tarigan. 2006. Hukum Perdata Islam di Indonesia: Studi Kritis Perkembangan Hukum Islam dari Fikih, UU No. 1/1974 Sampai KHI. Jakarta: Kencana.

Palmer. 1981. Semantics. Cambridge: Cambridge Universty Press.

Pateda. 2001. Semantik Leksikal. Jakarta: PT Gramedia.

Ramlan. 1983. Morfologi Suatu Tinjauan Deskriptif. Yogyakarta: CV Karyono.

Rohmadi, Muhammad. 2010. Analisis Wacana Pragmatik. Surakarta: Yunia Pustaka.

Sudaryat. 2009. Makna dalam Wacana. Bandung: CV Yrama Widya.

Sutedi. 2003. Hukum Hak Tanggungan. Jakarta: Sinar Grafika.

Takariawan, Cahyadi. 2004. Izinkan Aku Meminangmu. Solo: Era Intermedia. 